\title{
Sensitivity of the Mediterranean sea level to atmospheric pressure and free surface elevation numerical formulation in NEMO
}

\author{
P. Oddo ${ }^{1, *}$, A. Bonaduce ${ }^{2}$, N. Pinardi ${ }^{1,2,3}$, and A. Guarnieri ${ }^{1}$ \\ ${ }^{1}$ Istituto Nazionale di Geofisica e Vulcanologia, Bologna, Italy \\ ${ }^{2}$ Centro EuroMediterraneo per i Cambiamenti Climatici, Bologna, Italy \\ ${ }^{3}$ Università degli Studi di Bologna, Dipartimento di Fisica e Astronomia, Bologna, Italy \\ * now at: NATO Science and Technology Organization Centre for Maritime Research and Experimentation, \\ Viale San Bartolomeo 40019126 La Spezia, Italy \\ Correspondence to: P. Oddo (paolo.oddo@bo.ingv.it)
}

Received: 5 March 2014 - Published in Geosci. Model Dev. Discuss.: 18 June 2014

Revised: 27 October 2014 - Accepted: 12 November 2014 - Published: 17 December 2014

\begin{abstract}
The sensitivity of the dynamics of the Mediterranean Sea to atmospheric pressure and free surface elevation formulation using NEMO (Nucleus for European Modelling of the Ocean) was evaluated. Four different experiments were carried out in the Mediterranean Sea using filtered or explicit free surface numerical schemes and accounting for the effect of atmospheric pressure in addition to wind and buoyancy fluxes. Model results were evaluated by coherency and power spectrum analysis with tide gauge data. We found that atmospheric pressure plays an important role for periods shorter than 100 days. The free surface formulation is important to obtain the correct ocean response for periods shorter than 30 days. At frequencies higher than 15 days $^{-1}$ the Mediterranean basin's response to atmospheric pressure was not coherent and the performance of the model strongly depended on the specific area considered. A large-amplitude seasonal oscillation observed in the experiments using a filtered free surface was not evident in the corresponding explicit free surface formulation case, which was due to a phase shift between mass fluxes in the Gibraltar Strait and at the surface. The configuration with time splitting and atmospheric pressure always performed best; the differences were enhanced at very high frequencies.
\end{abstract}

\section{Introduction}

The Mediterranean Forecasting System (MFS, Pinardi and Flemming, 1989) started in the late 1980s, a time of growing interest in the operational framework of applied marine science. It now provides real-time environmental information about the Mediterranean Sea with continuously growing accuracy. The modelling component of the MFS is the focus of the present study.

The Ocean General Circulation Model (OGCM), which solves the primitive equations and integrates observational information for analyses and forecasts, has been enhanced continuously over the past 15 years. The evolution of the model can be traced back by referring to the related literature (Demirov and Pinardi, 2002 to Oddo et al., 2009). The current operational model consists of a code based on $\mathrm{Nu}-$ cleus for European Modelling of the Ocean (NEMO; Madec, 2008), under incompressible and hydrostatic approximation, with $1 / 16^{\circ}$ horizontal resolution and 72 vertical levels with partial cells, fully accounting for the air-sea fluxes by dedicated bulk formulae, connected to the global model (Drévillon et al., 2008). It also takes account of the fresh water input from the major Mediterranean rivers (details on the implementation of the model can be found in Oddo et al., 2009).

The NEMO code solves a prognostic equation for the sea surface elevation, and the induced external gravity waves (EGWs) are currently treated using a filter approach developed by Roullet and Madec (2000) that allows for a longer time-step, saving computational time. In version 3.3, the time-splitting technique was introduced into the NEMO code according to Griffies (2004), allowing for an explicit representation of the EGWs.

The sea level and its variability have a strong social and economic impact which explains the growing interest worldwide in the correct estimate of their evolution, in both time and space. The MFS is one example of the considerable effort spent in trying to achieve such accuracy. 
In the open ocean the response of the sea level to atmospheric pressure is close to the inverse barometer (IB) effect (Wunsch, 1972; Ponte, 1993). The classical IB approximation formulates the static response of the ocean to atmospheric pressure forcing. Atmospheric pressure effects in numerical ocean models, especially when solving large-scale problems, have often been neglected because of the relatively small amplitude of the horizontal gradients and following the assumption that the major influence is almost stationary and can be computed by superimposing an IB effect on the free surface solution without atmospheric pressure. However, oceanic responses to atmospheric pressure forcing can depart from a pure inverse barometer effect under specific circumstances, especially in the presence of geometrical constraints (i.e. straits or channels) (Garrett and Majaess, 1984) as in the Mediterranean Sea (Le Traon and Gauzelin, 1997; Pasaric et al., 2000). The validity of this IB assumption depends also on the timescales and space scales considered: the ocean response to atmospheric pressure generally differs from the IB for periods less than 3 days and at high latitudes. However, in closed or semi-enclosed seas, such as the Mediterranean, the response is more complex.

Sea-level variations in the Mediterranean Sea at timescales from 1 to 10 days have been shown to be primarily due to surface pressure changes related to synoptic atmospheric disturbances (Kasumovic, 1958; Mosetti, 1971; Papa, 1978; Godin and Trotti, 1975; Gomis et al., 2006; Pascual et al., 2008). On the other hand, sea-level variations at lower timescales have been explained as due to atmospheric planetary waves (Orlić, 1983). A significant contribution of the atmospheric pressure on the sea-level seasonal and interannual variability has been also documented (Gomis et al., 2006, 2008; Marcos and Tsimplis, 2007). It has been also observed that a significant departure from a standard IB effect can occur at frequencies higher than 30 days $^{-1}$ (Le Traon and Gauzelin, 1997). Departures from the IB response may be due to either local winds (Palumbo and Mazzarella, 1982) or the restrictions at straits on water transport between basins (Garret, 1983; Garrett and Majaess, 1984). Crépon (1965) has also shown that the response of a rotating fluid is never barometric. It may be quasi-barometric if the space scale of the atmospheric disturbance is smaller than the barotropic radius of deformation. He also showed that the larger the bottom friction, the closer is the response to barometric pressure. Furthermore, coastal Kelvin waves or other fast barotropic waves can support or accelerate the barometric adjustment. Atmospheric pressure driven flows through the Mediterranean straits lead to mass, momentum and vorticity exchanges between the connecting basins (Candela and Lozano, 1994).

It is thus clear that the dynamics of the Mediterranean Sea forced directly and indirectly by atmospheric pressure cover a large spectrum of processes with different temporal and spatial scales. We thus believe that the sensitivity of the dynamics induced by atmospheric pressure to the numerical formulation used to solve the surface elevation equation is an important area for investigation.

Section 2 describes the pressure formulation adopted in NEMO, together with the numerical schemes implemented to solve the sea-level equation. Details on the NEMO implementation and experimental set-up are described in Sect. 3. Model simulation results of the Mediterranean response to the atmospheric pressure and sensitivity to the numerical scheme used to solve the sea-level equation are discussed in Sect. 4. Section 5 provides a summary and conclusions.

\section{The pressure formulation}

Considering the hydrostatic approximation, the pressure $(p)$ at depth $z$ can be obtained by integrating the vertical component of the equation of motion from $z$ to the free surface $(\eta)$ :

$p(x, y, z, t)=p_{\mathrm{atm}}+g \rho_{0} \eta+g \int_{z}^{0} \rho(x, y, z, t) \mathrm{d} z$,

where the first term on the r.h.s. is the atmospheric pressure at the sea surface, the second term is the pressure due to the free surface, $\eta$, displacement, $\rho_{0}$ is the constant density value, and the last term on the r.h.s. is the hydrostatic pressure (where $\rho$ is density).

Introducing the separation (1) requires the addition of a diagnostic or prognostic equation for $\eta$. Rigid lid models use different methods to solve the diagnostic problem for $\eta$ (Dukowicz et al., 1993; Pinardi et al., 1995), but we will concentrate only on the prognostic formulation. The timedependent equation for $\eta$ is obtained by vertically integrating the continuity equation (under the incompressible approximation) and by applying surface and bottom dynamic boundary conditions:

$\frac{\partial \eta}{\partial t}=-D+P+R-E$,

where

$D=\nabla \cdot\left[(H+\eta) \bar{U}_{\mathrm{h}}\right]$

and

$\bar{U}_{\mathrm{h}}=\frac{1}{H+\eta} \int_{-H}^{\eta} \bar{u}_{\mathrm{h}} \mathrm{d} z$

is the barotropic velocity field, $\bar{u}_{\mathrm{h}}$ is the horizontal threedimensional velocity, $H$ is the bottom depth, $P$ is the precipitation, $R$ is the runoff divided by the river cross-sectional area, and $E$ is the evaporation.

The atmospheric pressure influences the horizontal velocity tendency which modifies the barotropic velocity field (4), 
which in turn changes the horizontal divergence of the momentum (3); this affects the $\eta$ tendency (2) which, again, modifies the total pressure.

Thus it is interesting to investigate how atmospheric pressure forcing influences the solution of primitive equations depending on the numerical schemes adopted to solve the prognostic Eq. (2).

The free-surface elevation response to atmospheric pressure may be composed of EGWs. Their timescale is short compared to other processes described by primitive equations and thus they require a very small time-step. Two methods are implemented in NEMO to allow a longer time-step, solving the primitive equation in the presence of EGWs: the so-called filtered and time-splitting methods.

NEMO users can decide between the two methods depending on the physical processes of interest. For fast EGWs, i.e. Poincaré or coastal Kelvin waves, time splitting is the most appropriate choice. If the focus is not on EGWs, a filter can be used to slow down the fastest waves while not altering the slow barotropic Rossby waves.

The filtering of EGWs in numerical models with a free surface is usually a matter of the discretization of the temporal derivatives. In the NEMO code, however, a slightly different approach developed by Roullet and Madec (2000) is used: the damping of EGWs is ensured by introducing an additional force in the momentum equation.

The time-splitting formulation used in NEMO follows the one proposed by Griffies (2004). The general idea is to solve the free surface equation and the associated barotropic velocity equations with a smaller time-step than the one used for the three-dimensional prognostic variables.

In this study we focus on the two different NEMO methods to solve the surface elevation Eq. (2), and on how these methods affect the reproduction of the atmospheric pressure induced dynamics.

\section{Experimental set-up}

\subsection{NEMO model configuration}

Four different physical and numerical configurations of NEMO were used to test and analyse the sensitivity of the model results on the atmospheric pressure forcing and the numerical scheme adopted to solve the surface elevation equation. The NEMO configurations used in this study are ultimately derived from the NEMO v3.2 model described by Oddo et al. (2009). This is the ocean modelling component of the MFS (Pinardi et al., 2003), hereafter NEMO-MFS1. Since the original publication of Oddo et al. (2009), the NEMO model has undergone a series of revisions and is now used at v3.4. However, the results described in Oddo et al. (2009) can traceably be reproduced using the current v3.4 version of NEMO.
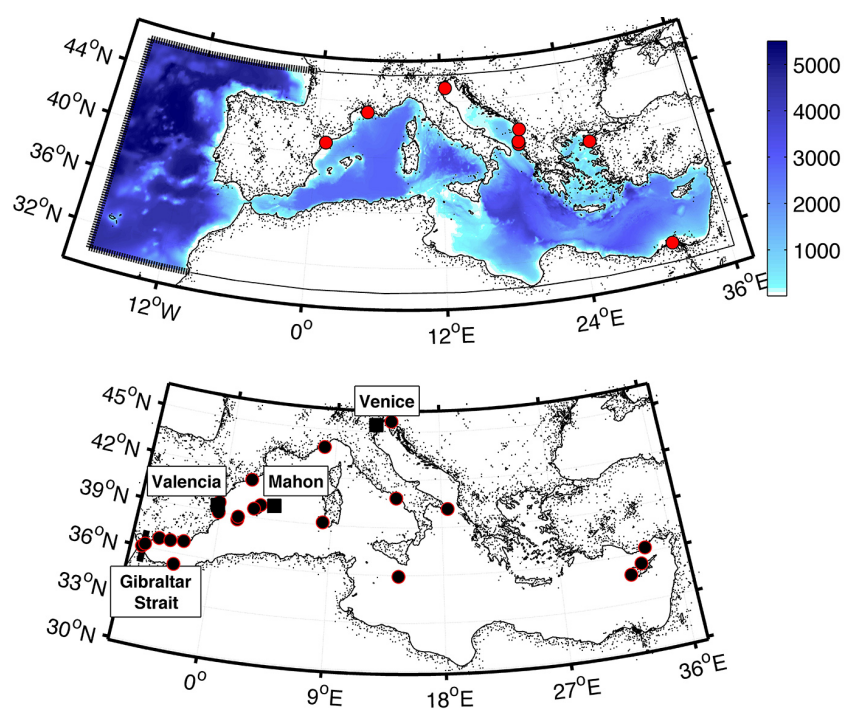

Figure 1. Upper panel: model domain. Bold dashed lines in the Atlantic indicate the location of the lateral boundaries of the model. Red circles indicate river locations and Dardanelles inflow. Bottom panel: black circles indicate tide gauge positions. Dark squares indicate the positions of the tide gauges collecting high-frequency data. The Gibraltar Strait is also shown.

In this study, NEMO-MFS-1 is based on NEMO 3.4 code version using a filtered free surface with a $1 / 16^{\circ}$ horizontal regular resolution, and 72 unevenly spaced vertical $z$ levels with partial cells to fit the bottom depth shape. NEMOMFS-1 covers the entire Mediterranean Sea and also extends into the Atlantic (Fig. 1, upper panel). The model is forced by momentum, water and heat fluxes interactively computed by bulk formulae (Oddo et al., 2009) using the $6 \mathrm{~h}, 0.5^{\circ}$ horizontal-resolution operational analyses from the European Centre for Medium-Range Weather Forecasts (ECMWF) and model-predicted surface temperatures. The ECMWF fields are linearly interpolated onto the model time-step. Atmospheric pressure effects are not included in the model forcings. The natural surface boundary condition for vertical velocity is used.

Only seven major rivers were implemented (Fig. 1, upper panel): the Ebro, Nile and Rhone monthly values are from the Global Runoff Data Centre (Fekete et al., 1999), the Adriatic rivers Po, Vjose and Seman are from Raicich (Raicich, 1996), while the Bojana River climatological flow is taken from UNEP (1996). The Dardanelles inflow was parameterized as a river and its monthly climatological net inflow rates and salinity values were taken from Kourafalou and Barbopoulos (2003).

The advection scheme for active tracers is a mixed upstream/MUSCL scheme (Monotonic Upwind Scheme for Conservation Laws, Van Leer, 1979, as implemented by Estubier and Levy, 2000). The up-stream scheme is used in proximity of the river mouths, in the Gibraltar Strait and close to the lateral open boundaries in the Atlantic. In Gibral- 
Table 1. NEMO-MFS configurations with corresponding cpp keys and namelist variables.

\begin{tabular}{|c|c|c|c|c|}
\hline & \multicolumn{4}{|c|}{ NEMO } \\
\hline & MFS-1 & MFS-2 & MFS-3 & MFS-4 \\
\hline Horiz. resolution & \multicolumn{4}{|c|}{ 1/16 Degree } \\
\hline Vertical discretization & \multicolumn{4}{|c|}{$72 \mathrm{z}$ levels with partial cells. (ln_zps $=$.true.) } \\
\hline Horiz. viscosity & \multicolumn{4}{|c|}{ Bi-Laplacian $A_{\mathrm{mh}}=5 \mathrm{e} .9 \mathrm{~m}^{4} \mathrm{~s}^{-1}($ ln_dynldf_bilap $=$. true.$)$} \\
\hline Horiz. diffusivity & \multicolumn{4}{|c|}{ Bi-Laplacian $A_{\mathrm{th}}=-3 . \mathrm{e} 9 \mathrm{~m}^{4} \mathrm{~s}^{-1}($ ln_traldf_bilap $=. t r u e)}$. \\
\hline Vertical visc. scheme & \multicolumn{4}{|c|}{ Pacanowski and Philander (key_zdfric) } \\
\hline Free-surface formulation & & $\begin{array}{c}\text { Filtered } \\
\left(k e y \_d y n s p g \_f t\right)\end{array}$ & \multicolumn{2}{|c|}{$\begin{array}{l}\text { Time splitting } \\
\text { (key_dynspg_ts) }\end{array}$} \\
\hline Time-step & \multirow{2}{*}{\multicolumn{4}{|c|}{$\begin{array}{l}\text { Number of barotropic sub-time steps } n n \_ \text {baro }=100 \\
\text { MedAtlas climatology }\end{array}$}} \\
\hline Initial condition & & & & \\
\hline Air-sea fluxes & \multicolumn{4}{|c|}{ MFS-bulk formulae $\left(l n \_b l k \_m f s=\right.$.true. $)$} \\
\hline Atmospheric press. & No & Yes & No & Yes \\
\hline ln_apr_dyn $=$ & false. & true. & false. & .true. \\
\hline Runoff & \multicolumn{4}{|c|}{ As surface boundary condition for $S$ and $w\left(\ln \_r n f=. t r u e.\right)$} \\
\hline Solar radiation & \multicolumn{4}{|c|}{2 Bands penetration $\left(l n \_q s r \_2 b d=. t r u e.\right)$} \\
\hline Lateral momentum B.C. & \multicolumn{4}{|c|}{$\begin{array}{l}\text { No-sleep } \\
\left.r n \_s h l a t=2 .\right)\end{array}$} \\
\hline Bottom momentum B.C & \multicolumn{3}{|c|}{$\left(n n \_b f r=2\right)$} & \\
\hline EOS & \multicolumn{4}{|c|}{ UNESCO - Jackett and McDougall (1995) $(n n$ eos $=0)$} \\
\hline Tracer advection & \multicolumn{4}{|c|}{ Up-stream/MUSCL (ln_traadv_muscl = .true. $)$} \\
\hline Momentum advection & \multicolumn{4}{|c|}{$\begin{array}{l}\text { Vector form (energy and enstrophy cons. scheme) } \\
\left(\ln d y n a d v \_v e c=. t r u e . \ln \text { dynvor_een }=. \text { true. }\right)\end{array}$} \\
\hline Back. vertical visc. & \multicolumn{4}{|c|}{$A_{\mathrm{my}}=1.2 \mathrm{e}-5 \mathrm{~m}^{2} \mathrm{~s}^{-1}$} \\
\hline Back. vertical diff. & \multicolumn{4}{|c|}{$A_{\mathrm{tv}}=1.2 \mathrm{e}-6 \mathrm{~m}^{2} \mathrm{~s}^{-1}$} \\
\hline Vertical visc./diff. scheme & \multicolumn{4}{|c|}{ Implicit $\left(l n \_z d f \exp =\right.$.false. $)$} \\
\hline
\end{tabular}

tar, the up-stream scheme, together with an artificially increased vertical diffusivity, parameterizes the mixing that acts in this area due to the internal wave breaking, which is not explicitly resolved by the model.

In NEMO-MFS-1, the Atlantic box is nested within the monthly mean climatological fields computed from the daily output of the $1 / 4^{\circ}$ global model (Drévillon et al., 2008), spanning from 2001 to 2005. The two-dimensional adaptive radiation condition (Marchesiello et al., 2001; Oddo and Pinardi, 2008) was used for the active tracers (temperature and salinity). Total velocities at the open boundaries are imposed by the global model solution, while barotropic velocities use a modified Flather (1976) lateral boundary condition explained by Oddo and Pinardi (2008). A summary of the model configuration is provided in Table 1, while details on the lateral open boundaries conditions are provided by Oddo et al. (2009).

Three additional NEMO configurations were created for this study. NEMO-MFS-2 is identical to NEMO-MFS-1 except for the inclusion of the atmospheric pressure forcing. This forcing, like the other atmospheric fields, is taken from ECMWF operational products. NEMO-MFS-3 uses the timesplitting approach to solve the free surface elevation tendency Eq. (2), without considering the atmospheric pressure. Finally NEMO-MFS-4 uses the time-splitting method and also takes account of the atmospheric pressure effects. The differences between the four model configurations are listed in Table 1 while Appendix A provides details on how to reproduce the physical set-up used in this manuscript starting from the standard NEMO code.

All the simulations have been initialized with climatological temperature and salinity fields (SeaDataNet, www. seadatanet.org) on 7 January 2004 and ended on 31 December 2012 .

\section{Results and discussion}

In this section the sensitivity of the circulation response due to the atmospheric pressure effect is analysed as a function of the free surface elevation formulation in NEMO. Only the different solutions for $\eta$ are considered since vertical profiles of temperature and salinity were not found to be significantly different among the four experiments. All the model configurations have very similar baroclinic capabilities to each other and to the ones obtained with similar NEMO experiments (Oddo et al., 2009).

To assess the accuracy of the model and to corroborate the numerical findings, sea-level data retrieved from several tide 

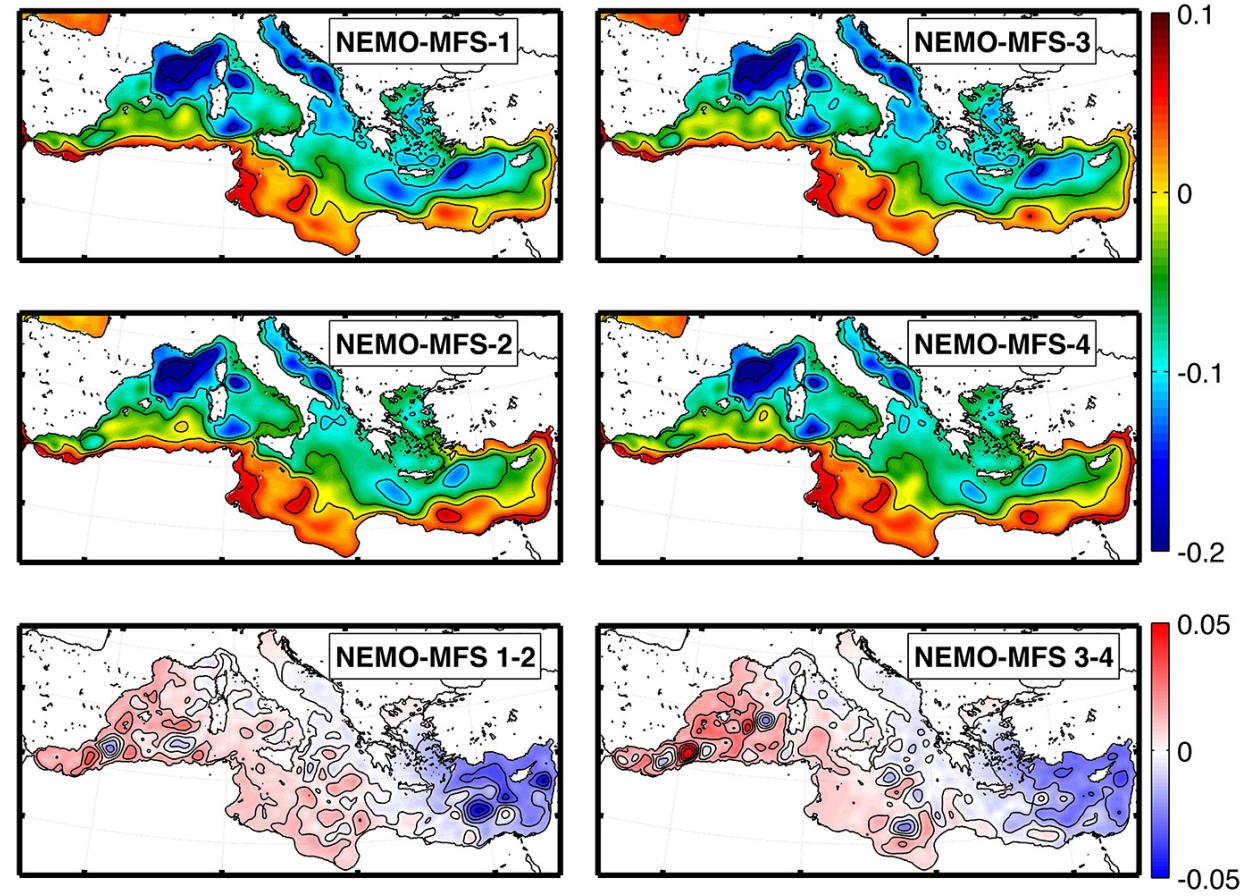

Figure 2. Horizontal maps of the 2-year mean component of the sea surface elevation in the four experiments (units are metres). The two bottom panels represent the sea surface elevation differences between the experiments with and without atmospheric pressure forcing for the time-splitting (right) and the filtered free surface (left) cases.

gauges in the Mediterranean Sea were used (Fig. 1, bottom panel).

Since the Mediterranean's response to atmospheric pressure forcing varies according to the timescales considered (Garret and Majaess, 1984; Lascaratos and Gačić, 1990), model results are analysed and discussed on the basis of different temporal scales. Firstly the low-frequency response results are discussed in terms of model-to-model and modelsto-observations comparisons in a period range spanning from the time-invariant components of the $\eta$ signal up to 5 days. The high-frequency model results are then analysed in a period window from 5 days to $12 \mathrm{~h}$.

\subsection{Low-frequency components}

The 2-year mean component of the sea surface height (SSH) in the four experiments is shown in Fig. 2. At climatological timescales there are no significant differences between the two $\eta$ numerical formulations; however, qualitative differences in the circulation due to the introduction of pressure forcing are evident. The major Mediterranean circulation structures (Pinardi et al., 2013) are very similar among the various numerical model formulations but different due to the introduction of atmospheric pressure forcing. This forcing generally weakens all the cyclonic wind-driven structures as the atmospheric pressure forces $\eta$ in the opposite way from the wind stress curl, i.e. the wind strengthens the cyclonic structures, whereas the associated atmospheric pres- sure weakens them. The Adriatic and the Rhode cyclonic gyre circulations illustrate the atmospheric pressure effects well, and the structures are more realistic and closer to recent Mediterranean circulation reanalysis studies (Pinardi et al., 2013) in the atmospheric forcing cases.

The maps showing differences between the experiments with and without atmospheric pressure are also similar. A large-scale zonal gradient in the free surface is observed due to atmospheric pressure which produces higher $\eta$ values in the Levantine basin and lower $\eta$ values in the western Mediterranean Sea. Similar standard deviations maps (not shown) also indicate that, when atmospheric pressure is introduced, the Levantine basin has larger seasonal oscillations than the remaining part of the Mediterranean Sea. In the various experiments, small-scale differences, i.e. eddy-like structures, were observed. These structures have horizontal scales that are much smaller than the atmospheric pressure scales and are probably due to the displacements of oceanic features as a consequence of instabilities induced by the new forcing.

A comparison between the time-series of daily values of $\eta$ for the four experiments and corresponding observed data are shown in Fig. 3. Prior to the comparison, the steric effect was superimposed on the $\eta$ model outputs, following Mellor and Ezer (1995). A time interval from July 2010 to July 2012 was selected, since a significant number of station data are available. The results were also evaluated by a 

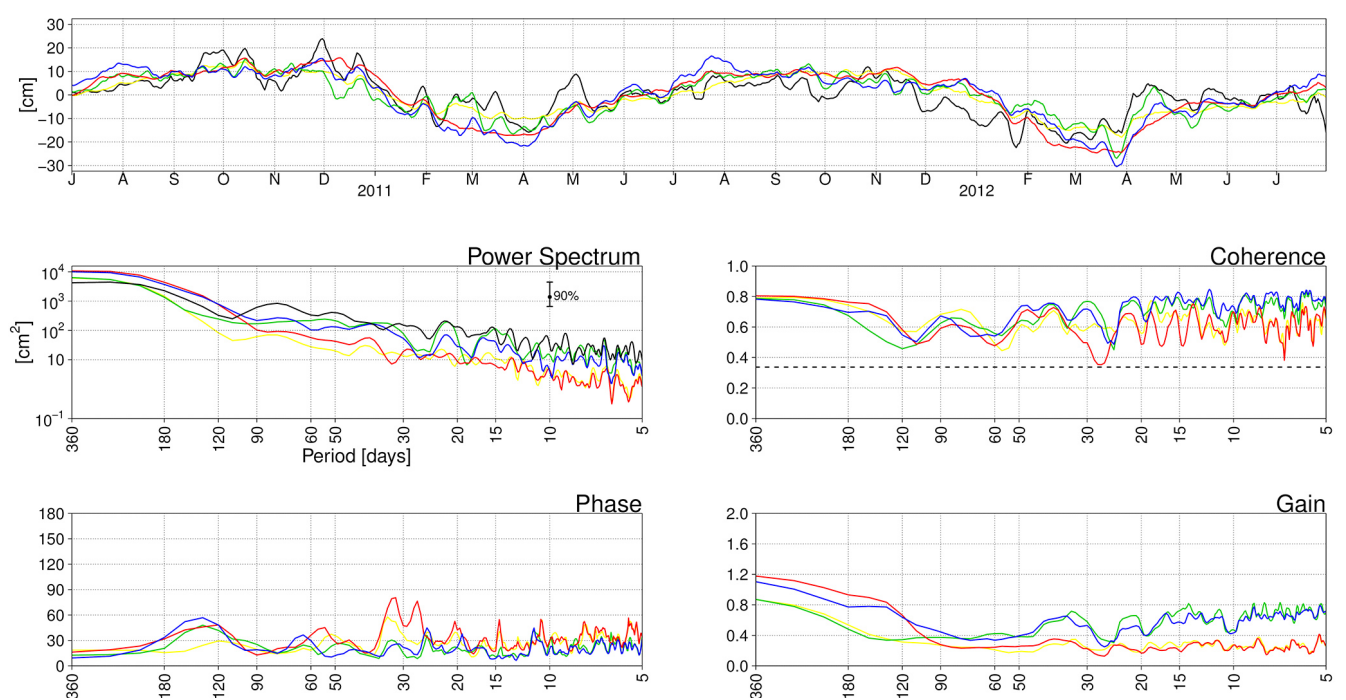

Figure 3. Top panel: Mediterranean mean sea-level time-series from the four experiments and observations averaged over the tide gauge positions shown in Fig. 1. The black line represents observational data, the red line represents NEMO-MFS-1 results, the blue line represents NEMO-MFS-2 results, the yellow line represents NEMO-MFS-3 results, and the green line represents NEMO-MFS-4 results. Left middle panel: $\eta$ power spectra for observations and model results, units are $\mathrm{cm}^{2}$. Right middle, left bottom and right bottom panels: coherence, phase (degrees) and gain computed between observations and model, respectively. Units in the $x$ axis are periods in days.

power spectra comparison and coherency analysis with observations. For the coherency analysis smoothing was performed over eight adjacent frequencies. Model results were first interpolated into the tide-gauge positions (Fig. 1, bottom panel) and then averaged. In order to evaluate potential sampling errors deriving from the relatively short time interval analysed and statistical robustness of the model results, a preliminary spectral analysis has been carried out considering the entire model runs period. In terms of the energetic content and differences between the different model configurations, no significant differences have been observed between the two time periods considered. Results are shown for periods between 360 and 5 days. However, results for periods shorter than 15 days were shown to be sensitive to specific sampling positions and/or tide gauge locations (in agreement with Garret and Majaess, 1984; Lascaratos and Gačić, 1990). On the other hand, the modelled response to the atmospheric pressure in the period band between 360 and 15 days was shown to be geographically coherent within the Mediterranean basin.

In agreement with Molcard et al. (2002) and Oddo et al. (2009) and irrespective of the experiment considered, both observational and modelled data are characterized by a large seasonal cycle modulated by inter-annual variability (the inter-annual variability is not shown, since only a 2-year interval series was selected from the model results in order to be consistent with the observational data set available). Qualitatively, the longer timescales of the inter-annual variability have larger amplitudes in the winter than in the summer. At very low frequencies the major difference in the results deriving from the two free surface methods is the amplitude of the seasonal cycle, i.e. the filtered formulation has a larger amplitude.

Comparing the power spectra (Fig. 3, left-middle panel), it is evident that the filtered formulation overestimates the energy content in the spectral window between 360 and 120/100 days. The introduction of the atmospheric pressure slightly reduces this model behaviour (Fig. 3, right-bottom panel). For shorter periods, between 120 and 5 days, the filtered formulation generally underestimates the energy content. Also in this case, when the atmospheric pressure in the filtered formulation was introduced, there was a considerable improvement in the reproduction of the energy content.

Overall, the two experiments with the time-splitting formulation improved the reproduction of the observed energy content. At seasonal scales, the energy content is considerably lower than the filtered simulations and is closer to the observation. However in the window between 180 and 30 days, NEMO-MFS-3 significantly underestimated the observed variability due to the missing contribution of atmospheric pressure in this period range.

At frequencies between 100 and 5 days $^{-1}$ NEMO-MFS3 and NEMO-MFS-1 without atmospheric pressure forcing have very similar energy contents and both underestimated the observed values.

As for the filtered formulation, with the introduction of the atmospheric pressure in the time-splitting experiments, the energy content of $\eta$ increases in the spectral window between 120 and 5 days, reaching generally closer values to the observations. In terms of energy content, introducing the atmospheric pressure has a significant impact for periods shorter than 120/100 days (see the "Gain" panel in Fig. 3). For pe- 

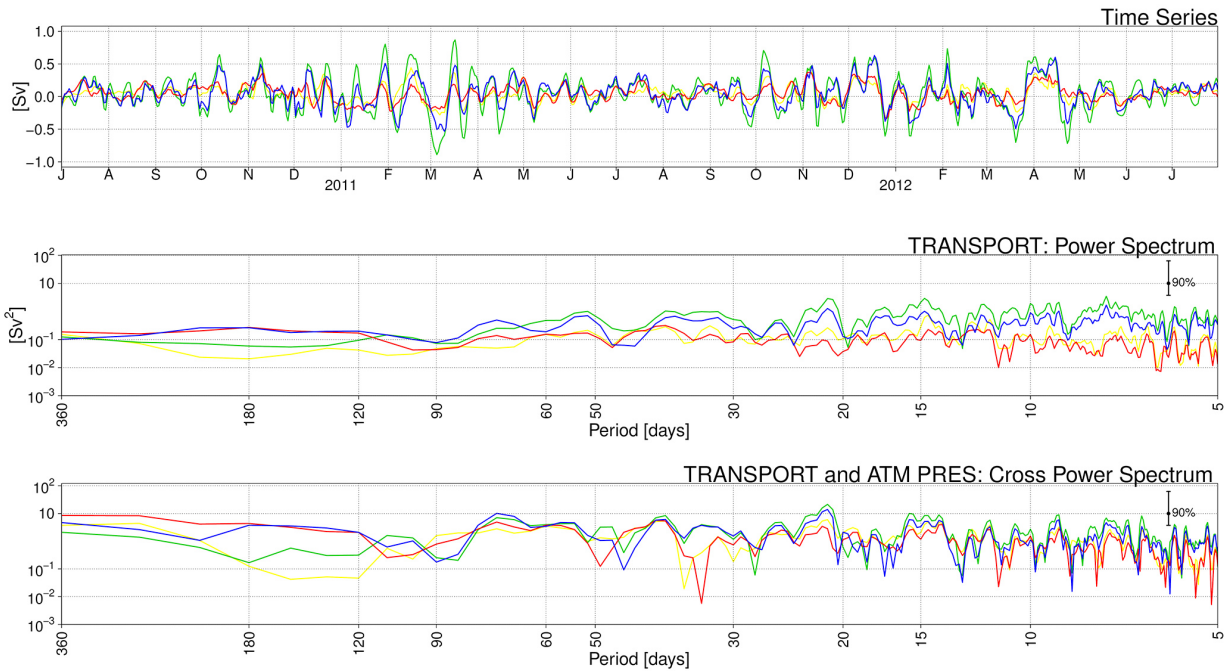

Figure 4. Top panel: Gibraltar transport time-series from the four experiments. Middle panel: Gibraltar transport power spectra. Bottom panel: cross power spectrum between Gibraltar transport and atmospheric pressure. NEMO-MFS1, red; NEMO-MFS2, blue; NEMO-MFS3, yellow; NEMO-MFS4, green.

riods longer than 120/100 days, the numerical scheme used to solve Eq. (2) plays a major role in determining the ocean dynamic (irrespective of the additional forcing introduced), while for periods shorter than 120/100 days, the effect of atmospheric pressure dominates over the effect of the specific numerical solution method for $\eta$.

In all the experiments, the coherence is fairly high (Fig. 3, right-middle panel). There were significant improvements with the introduction of the atmospheric pressure, irrespective of the numerical solution methods, for periods shorter than 50 days. The phase difference is always small and generally below $30^{\circ}$. There was a significant phase shift between observations and model simulation values between 40 and 25 days in the absence of atmospheric pressure forcing. For periods shorter than 180 days, all the gains are generally smaller than 1, which means that the model underestimated the amplitude of $\eta$ oscillations. However there was a significant improvement with introduction of the atmospheric pressure forcing for periods shorter than 90 days.

The analysis so far was performed for the model and observed average sea level at the 25 tide gauge stations (Fig. 1). This can be considered a good estimate of the mean sea level of the Mediterranean Sea for periods between 360 and 15 days because no significant differences were observed at these timescales, averaging over the whole Mediterranean Sea or by only sampling at tide gauge locations.

To elucidate the observed differences between the results of the four experiments in terms of these basin averaged oscillations, Fig. 4 shows the time-series of net transport at the Gibraltar Strait together with the corresponding power and cross power (with atmospheric pressure) spectra. The mean net transport in the four experiments does not vary significantly, i.e. the time averages are all about $0.05 \mathrm{~Sv}$ (in agreement with previously modelled and observed findings; Oddo et al., 2009). On the other hand, in agreement with Lacombe (1961), introducing the atmospheric pressure led to a significant increase in the amplitude of the transport oscillations for periods shorter than 100 days. Furthermore, important sub-inertial variability in the period band of 10-5 days is observed, while annual or semi-annual signals have small amplitudes, confirming previous studies' results (Lafuente et al., 2002).

For periods longer than 270 days, introducing the atmospheric pressure dampens the amplitude of the transport whichever numerical formulation is used for the free surface elevation, but this effect was larger using the filtered scheme (Fig. 4, middle panel). In the range of 270 and 120 days, the NEMO-MFS- 1 and NEMO-MFS-2 simulated transport had a larger energy content than the corresponding NEMO-MFS-3 and NEMO-MFS-4. Between 70 and 30 days, the introduction of atmospheric pressure produced a similar increase in energy content in both the configurations (filtered and timesplitting formulations).

For periods shorter than 25 days, there were clearer differences in atmospheric pressure effect in the two formulations. In these spectral windows, the oscillation in the Gibraltar transport was totally due to the atmospheric pressure-induced dynamics. Peaks in the spectra and in the cross power spectra simulated with the time splitting match peaks simulated using the filtered formulations. However, using time splitting, the energy content doubled, meaning that the atmospheric pressure effect in the Gibraltar Straits must occur in the form of fast processes filtered out using the filtered formulations.

Note that the different amplitude of the seasonal cycle of the average sea surface elevation in the two model formulations is not completely explained by the corresponding en- 

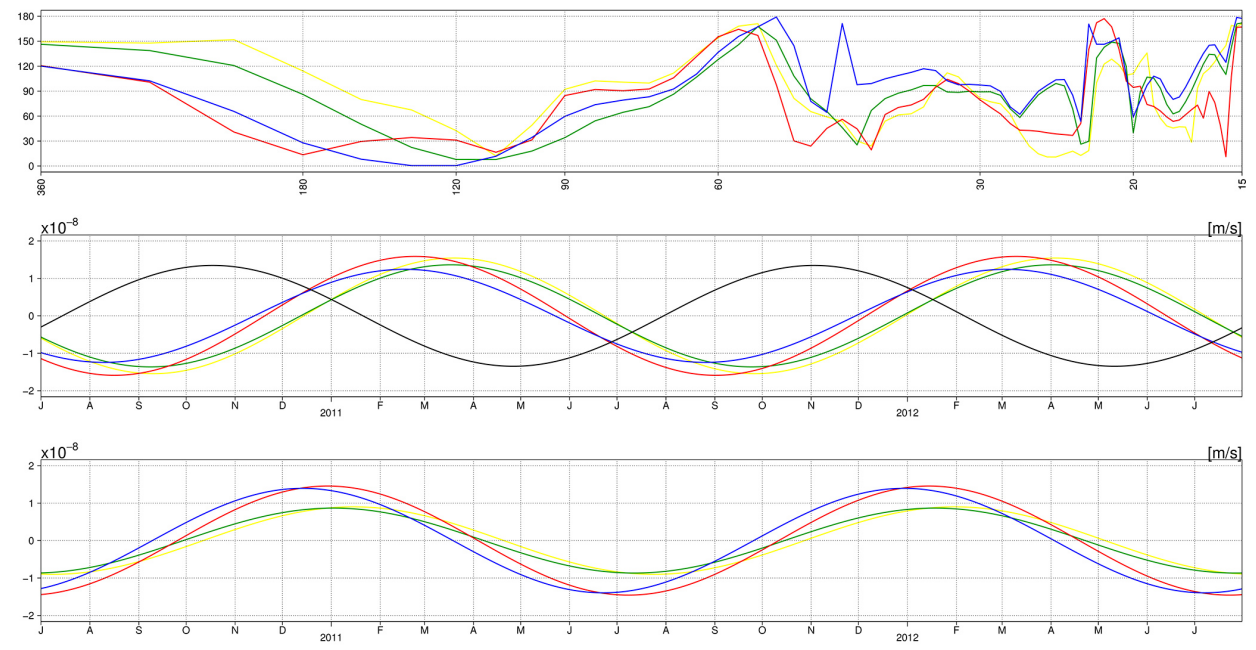

Figure 5. Top panel: phase analysis between Gibraltar transport and surface mass fluxes. Middle panel: Gibraltar transport for the four experiments and surface mass flux reconstructed using only seasonal frequencies. The black line indicates the surface mass fluxes (identical in all the model simulations). Bottom panel: sea's surface height stochastic component for the four experiments reconstructed using only seasonal frequencies. NEMO-MFS1, red; NEMO-MFS2, blue; NEMO-MFS3, yellow; NEMO-MFS4, green.

ergy content of the Gibraltar transport. Similarly to Pinardi et al. (2014), by integrating Eq. (2) into time and into a semienclosed basin such as the Mediterranean Sea, we obtain an equation for the mean sea level tendency:

$\frac{\partial\langle\eta\rangle}{\partial t}=\frac{\text { Gib_tr }}{A}-\langle\mathrm{qw}$,

where Gib_tr is the integral of the mass divergence $D$ in Eq. (3) resulting in the net transport at Gibraltar, $A$ is the Mediterranean Sea area, and qw is the basin average of the surface mass fluxes, which is identical (not shown) in the four simulations. What modulates the mean sea surface elevation seasonal oscillation differently in the four experiments is the phase shift between the two terms on the right-hand side of Eq. (5). Pinardi et al. (2014) call this difference the stochastic component of the sea surface elevation tendency.

In Fig. 5 (top panel) the phases between the Gibraltar net transport and the surface mass flux (qw) for the four experiments are shown. The main differences derive from the introduction of the time-splitting scheme, while the atmospheric pressure plays a minor role in modulating the phase of the two signals at seasonal timescales. At higher frequencies (periods shorter than 100 days) the atmospheric pressure effect dominates. In the middle panel of Fig. 5, the Gib_tr and qw reconstructed signals considering only the seasonal frequencies are shown; the corresponding stochastic sea surface elevation component is shown in the bottom panel. Only one time-series of qw is drawn since no significant differences among the experiments are observed. The amplitude of the Gibraltar net transport annual cycle is very similar in all the considered model experiments and its value is about $0.07 \mathrm{~Sv}$; the qw seasonal cycle has an amplitude of about $0.06 \mathrm{~Sv}$. Both Gib_tr and qw modelled seasonal oscillations are in agreement with previous studies (Lafuente et al., 2002). The phase shift produced using the time-splitting scheme amplifies the phase difference between qw and Gib_tr (from 120 to 150 degrees), and the resulting stochastic component has a smaller amplitude. This could have a profound influence on the long-term trend in the sea level in the Mediterranean, as explained by Pinardi et al. (2014).

\subsection{High-frequency components}

To analyse the high-frequency response of the model to atmospheric pressure forcing and its sensitivity to the sea-level formulation for short periods, three tide gauge stations (Valencia, Mahon and Venice) were selected on the base of data availability. The data have a frequency of an hour and were analysed for a period of 6 months spanning from 2 November 2011 to 30 April 2012. The tide gauge positions are shown in Fig. 1 (bottom panel). The Mediterranean's response to atmospheric pressure varies spatially, as different processes characterize different areas of the basin. It is worth mentioning that the $6 \mathrm{~h}$ frequency ECMWF forcing field does not properly sample the full spectra of the atmospheric phenomena and aliasing problems may occur. Consequently the corresponding oceanic response could be only partially resolved by the NEMO configurations. Thus, some differences between modelled and observed sea level at high frequency could be due to the sampling frequency of the atmospheric data. Moreover, previous studies (Pascual et al., 2008; Wakelin and Proctor, 2002) have already proved the possibility to reproduce the energetic content of high-frequency (up to $4 \mathrm{~h}$ ) Mediterranean processes using similar atmospheric data (Wakelin and Proctor, 2002). Prior to the comparison, the tidal signal was removed from the observed data set and 


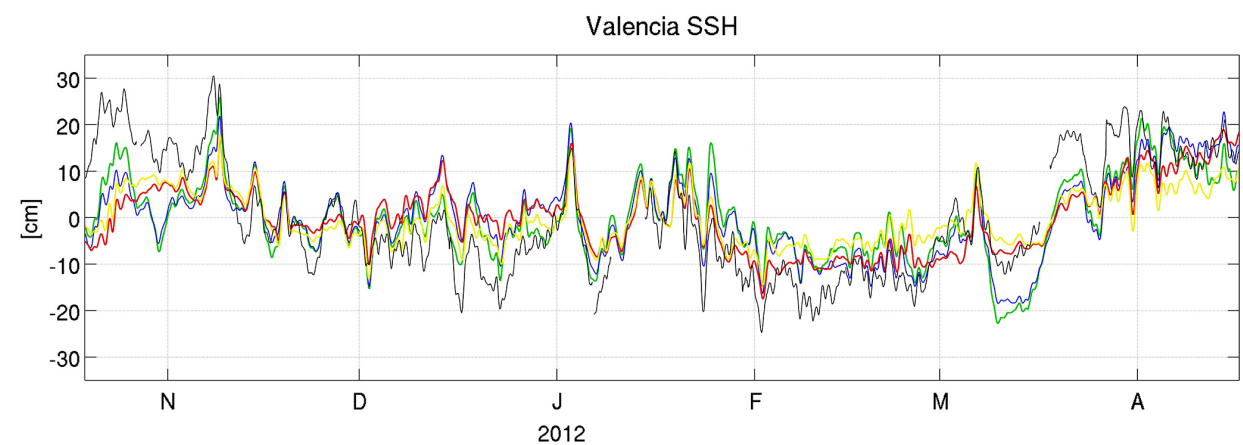

Figure 6. Valencia $\eta$ time-series from observations and model results. Data and model results have been filtered with $5 \mathrm{~h}$ running mean. Observations, black; NEMO-MFS1, red; NEMO-MFS2, blue; NEMO-MFS3, yellow; NEMO-MFS4, green.

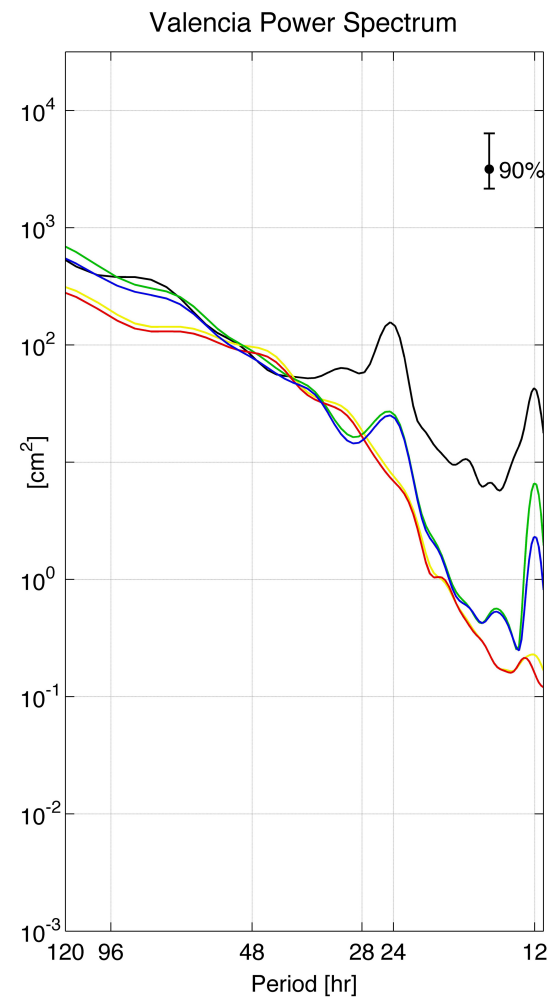

Figure 7. Valencia $\eta$ power spectra from observations and models results. Observations, black; NEMO-MFS1, red; NEMO-MFS2, blue; NEMO-MFS3, yellow; NEMO-MFS4, green.

steric effect superimposed on model results. Modelled and observed sea-level data time-series were also compared by analysing individual power spectra. Power spectra for the three selected stations are drawn in the period band between 5 days and $12 \mathrm{~h}$, while the simulated and observed energetic contents at very high frequencies (between 12 and $2 \mathrm{~h}^{-1}$ ) are listed in Table 2.

In Figs. 6 and 7 the sea-level time-series and power spectra are shown for the station in Valencia. The observed power spectrum is characterized by two distinct maxima, with 24 and $12 \mathrm{~h}$ periods respectively. At relatively low frequencies (lower than $48 \mathrm{~h}^{-1}$ ), the experiments without the atmospheric pressure underestimated the amplitude of the oscillations. In the range between 48 and $28 \mathrm{~h}$ all the experiments performed in a similar way. Differences between numerical schemes and additional forcing are more evident for periods lower than $28 \mathrm{~h}$. Experiments without the atmospheric pressure forcing, NEMO-MFS-1 and NEMO-MFS-3, strongly underestimated the amplitude of the signal. By introduction of the atmospheric pressure, the energetic level increased in both NEMO-MFS-2 and NEMO-MFS-4 and both the simulations capture the two observed relative maxima at 24 and $12 \mathrm{~h}$. At $24 \mathrm{~h}$ the two numerical formulations produce very similar results, both of which underestimate the observed energetic content. The NEMO-MFS-4 simulated energy is closer to the observed values than the corresponding NEMOMFS-2 result for higher frequencies $\left(12 \mathrm{~h}^{-1}\right)$.

The remaining part of the energetic spectra (frequencies higher than $12 \mathrm{~h}^{-1}$ ) is certainly affected by the relatively low frequency of the atmospheric forcing and a physical interpretation can be misleading. However, although all the model configurations strongly underestimate the observed energy content, NEMO-MFS-4 reaches energetic levels that are significantly higher than the other NEMO configurations (Table 2).

In Mahon a very similar sea-level behaviour was observed (Fig. 8), the only significant difference with Valencia being the high-frequency oscillation and the corresponding energetic levels for $18 \mathrm{~h}$ period (Fig. 9). However, in Mahon and Valencia, the model's sensitivity to atmospheric pressure and surface elevation schemes is different. The energetic levels' differences between the configurations with and without atmospheric pressure forcing for periods longer than $48 \mathrm{~h}$ are larger in Mahon than in Valencia, indicating that in Mahon the additional forcing plays a more important role in this period band. None of the models managed to reproduce the $24 \mathrm{~h}$ peak of the observed sea-level variability, i.e. Valencia was partially reproduced by introducing the additional forcing, and this could be due to insufficient resolution or inac- 
Table 2. Energy content $\left(\mathrm{cm}^{2}\right)$ in the period bands between 12 and $2 \mathrm{~h}$ in the three selected stations.

\begin{tabular}{lrrrrr}
\hline & Obs & NEMO-MFS1 & NEMO-MFS2 & NEMO-MFS3 & NEMO-MFS4 \\
\hline Valencia & 2400 & 4 & 16 & 5 & 165 \\
Mahon & 1900 & 1 & 5 & 2 & 20 \\
Venice & 2500 & 62 & 715 & 190 & 2400 \\
\hline
\end{tabular}

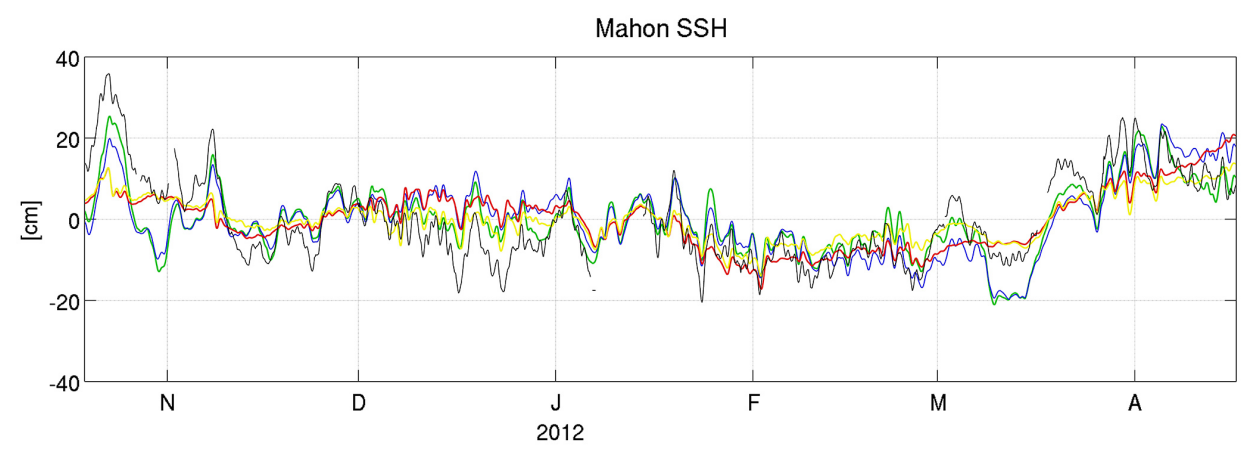

Figure 8. Mahon $\eta$ time-series from observations and model results. Data and model results have been filtered with $5 \mathrm{~h}$ running mean. Observations, black; NEMO-MFS1, red; NEMO-MFS2, blue; NEMO-MFS3, yellow; NEMO-MFS4, green.

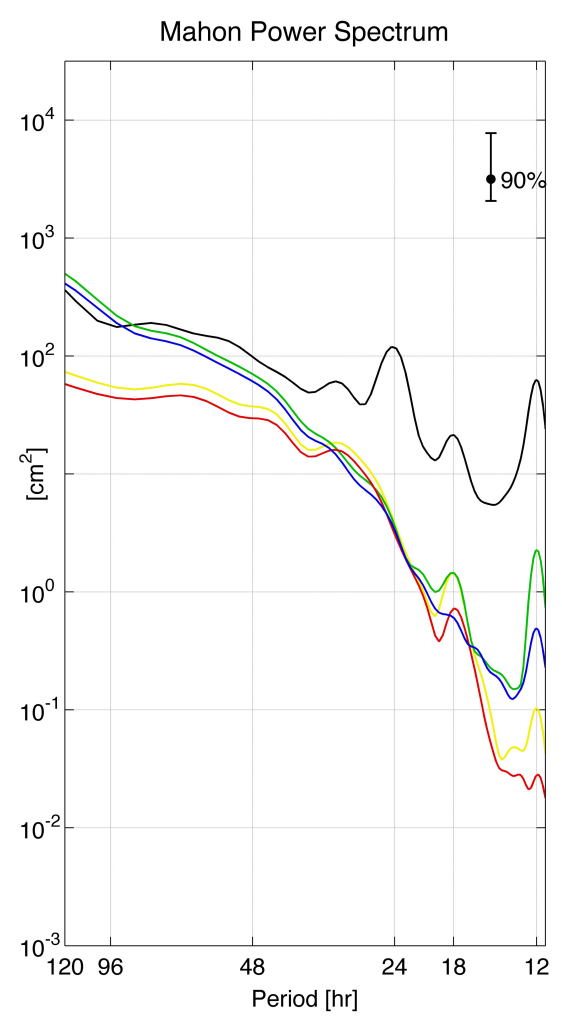

Figure 9. Mahon $\eta$ power spectra from observations and model results. Observations, black; NEMO-MFS1, red; NEMO-MFS2, blue; NEMO-MFS3, yellow; NEMO-MFS4, green. curate representation of the bathymetry. In Mahon, by introducing the atmospheric pressure and using the time-splitting scheme, there was a greater improvement in the representation of the $12 \mathrm{~h}$ period maximum although the modelled values remain lower than the observed ones. The $\eta$ formulation seems to play a minor role for periods longer than $18 \mathrm{~h}$, while the introduction of the atmospheric pressure forcing was responsible for the differences between the model results. In the spectral windows between 18 and $12 \mathrm{~h}$ the energetic levels obtained with the different configurations indicate that both additional forcing and the numerical scheme significantly improve the performance of the models. In the period band between 12 and $2 \mathrm{~h}$ (Table 2), none of the models managed to reproduce the observed energetic content.

The high-frequency sea-level data and corresponding power spectra for the Venice station are shown in Figs. 10 and 11, respectively. For most of the observed days, the sea level was characterized by the presence of seiches (Leder and Orlić, 2004). Since the Adriatic is characterized by the frequent passages of cyclones (apart from in the summer) and its geometry supports the existence of persistent free oscillations, energetic oscillations of the lowest basin mode seiches are prominent features of mareographic records (Cerovecki et al., 1997). This was also confirmed by the observed power spectra maxima at $22-23 \mathrm{~h}^{-1}$ and $12 \mathrm{~h}^{-1}$ frequencies (the frequencies of the main fundamental longitudinal oscillations in the Adriatic Sea; Raicich et al., 1999). All the model configurations capture these energy maxima, but significant differences in the energetic contents are evident. The introduction of the atmospheric pressure produces a similar energy increase in both the numerical and the $\eta$ formulations. 


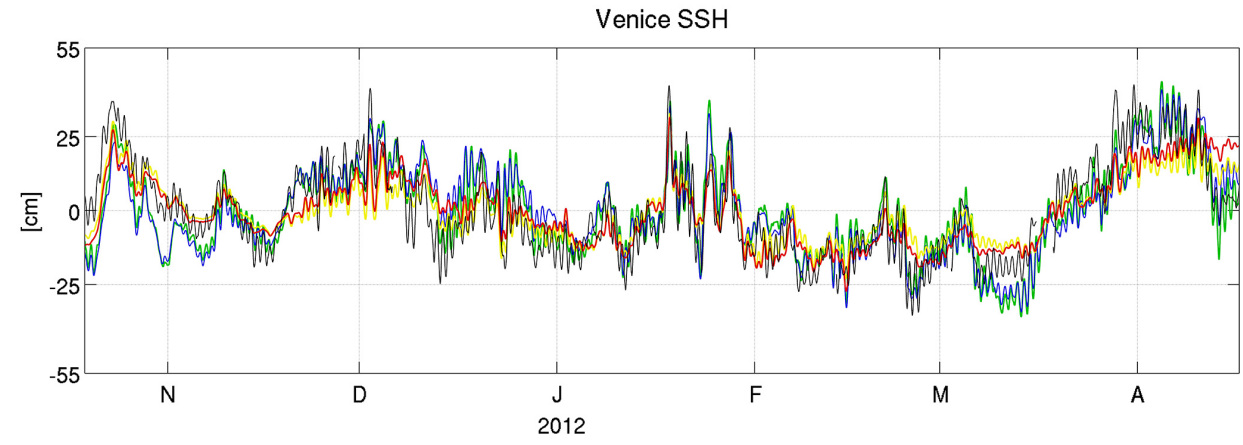

Figure 10. Venice $\eta$ time-series from observations and model results. Data and model results have been filtered with $5 \mathrm{~h}$ running mean. Observations, black; NEMO-MFS1, red; NEMO-MFS2, blue; NEMO-MFS3, yellow; NEMO-MFS4, green.

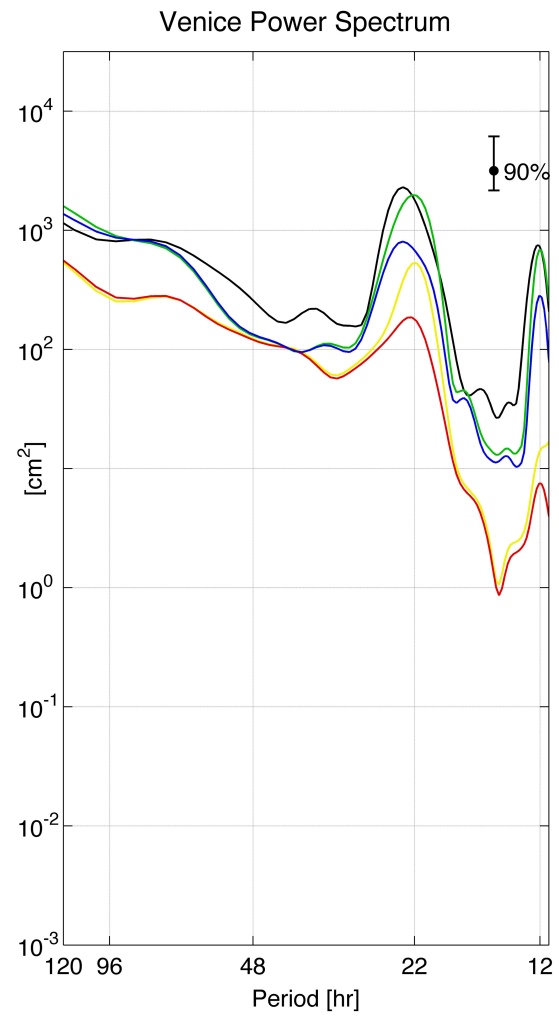

Figure 11. Venice $\eta$ power spectra from observations and model results. Observations, black; NEMO-MFS1, red; NEMO-MFS2, blue; NEMO-MFS3, yellow; NEMO-MFS4, green.

However, the energy content in the time-splitting formulation better matches the observed values. Without the atmospheric pressure, both the $\eta$ formulations clearly underestimate the amplitude of the free oscillations. The signal is only partially present in the model results (NEMO-MFS-1 and NEMO-MFS-3) due to the wind effect, which is also a driver for the seiches' dynamic (Leder and Orlić, 2004). In Venice the model's sensitivity to atmospheric pressure and $\eta$ formulation is significantly different from what was ob- served in Valencia and Mahon. In the latter two stations the different numerical scheme used to solve Eq. (2) affected the model results only for periods shorter than $18 / 16 \mathrm{~h}$, while in Venice differences are evident for $24 \mathrm{~h}$ period oscillations.

It is interesting to note that in the frequency band between 12 and $2 \mathrm{~h}^{-1}$ (Table 2), NEMO-MFS4 reaches and supports energetic levels similar to the observations, while the other models strongly underestimate the amplitude of the signal in this frequency band. A model configuration such as NEMOMFS4 might be able to correctly resolve the high-frequency dynamic of the Adriatic Sea if forced with adequate atmospheric data.

\section{Summary and conclusions}

The sensitivity of the Mediterranean Sea ocean dynamics to the free surface elevation numerical formulation in NEMO was evaluated for cases with and without atmospheric pressure forcings. Four different NEMO configurations were created and the results compared with each other and with available observations. All the NEMO configurations were implemented using the same horizontal and vertical meshes.

The reference NEMO configuration, NEMO-MFS-1, uses a filtered formulation of the free surface equation (Roullet and Madec, 2000) and does not take account of the atmospheric pressure effects. This model set-up is currently used in the framework of the MFS (Pinardi and Flemmings, 1989).

NEMO-MFS-2 differs from NEMO-MFS-1 due to the introduction of the atmospheric pressure forcing. The free surface equation is solved using a time-splitting approach (Griffies, 2004) which either does or does not account for the atmospheric pressure effect in NEMO-MFS-3 and NEMOMFS-4 configurations, respectively.

The spatial variability induced by the introduction of the atmospheric pressure in the 2-year mean component of the sea level was not influenced by the different numerical formulations used to solve the free surface equation (Fig. 2). However, the introduction of the atmospheric pressure induced a basin scale zonal sea level negative gradient (higher 
values in the east and lower in the west) and a weakening of all the cyclonic wind-driven structures irrespective of the free surface formulation adopted. The structure of the sea level and the corresponding circulation could be considered more realistic with atmospheric pressure forcing, although observational evidence is lacking at the basin scale.

At low frequencies, the major difference between the two numerical free surface formulations is the amplitude of the seasonal cycle. The filtered formulation overestimated the energy content in the spectral window between 400 and 120 days. The amplitude of the seasonal cycle in the timesplitting NEMO formulation was considerably smaller than in the filtered simulations and was closer to the observations. The introduction of atmospheric pressure slightly improved the filtered solution, but did not influence the time-splitting simulation results. With shorter periods (between 120 and 50 days), the simulations without the atmospheric pressure forcing generally underestimated the energy content.

For periods longer than 120/100 days, differences in the model numerical schemes led to quantitative differences in the sea level (irrespective of the atmospheric pressure), while for shorter periods, atmospheric pressure effects dominated.

In the analysed frequency windows, the time-splitting and filtered formulation responses to the introduction of atmospheric pressure were very similar; higher energy levels were reached with the time-splitting scheme and atmospheric pressure for short periods.

The mean net transport at the Gibraltar Strait in the four experiments did not vary significantly. At seasonal timescales, the introduction of the atmospheric pressure dampened the amplitude of the net transport in both the free surface numerical formulations. This effect was greater using the filtered scheme. In the periods longer than and 120 days, the NEMO-MFS-1 and NEMO-MFS-2 simulated transport had a larger energy content than the corresponding NEMOMFS-3 and NEMO-MFS-4 values. In addition, with the introduction of the atmospheric pressure, there was a significant increase in the amplitude of the transport oscillations for periods between 70 and 30 days.

At higher frequencies, the differences in the atmospheric pressure effect in the two sea-level formulations are more evident. In these spectral windows, the oscillation in the Gibraltar transport was totally due to the atmospheric pressure induced dynamics. With the use of time splitting, the energy content doubled.
An interesting finding of this study is the effect of the numerical scheme on the phase shift between Gibraltar transport and surface mass fluxes. This phase shift modulated the $\eta$ seasonal oscillation differently in the four experiments. The main differences in the four experiments derive from the introduction of the time-splitting formulation, while atmospheric pressure forcing plays a minor role in modulating the phase of the two signals at seasonal scales. The phase shift produced using time splitting amplifies the phase opposition between surface mass fluxes and the Gibraltar transport, and the resulting stochastic component of the sea-level tendency has a smaller amplitude.

An analysis of the observed and modelled high frequencies data sets in three different locations in the Mediterranean Sea (although two locations are relatively close to each other: Valencia and Mahon) highlights that the interaction between atmospheric pressure and barotropic dynamics follows different dynamics. In Mahon, an open ocean station in the western Mediterranean Sea (Fig. 1, bottom panel), the introduction of the atmospheric pressure forcing in the model improves the reproduction of the observed $\eta$ variability and energetic content in the spectral window between 20 and $12 \mathrm{~h}$. In Valencia, the additional pressure forcing affects the results of the model also for oscillations with $24 \mathrm{~h}$ period. On the other hand, in both stations the introduction of the atmospheric pressure allows the model to reach energetic levels similar to the observation for periods longer than $48 \mathrm{~h}$. In Venice, located in the northernmost part of a semi-enclosed basin and characterized by very shallow water, the introduction of the atmospheric pressure clearly improved the model's capability to correctly simulate the seiches, which, in addition to wind regimes, are driven by the atmospheric pressure differences between the north and south Adriatic. However, it is the explicit resolution of the barotropic processes (using the time splitting) that allows the model to correctly simulate the $\eta$ dynamics at high frequencies. 


\section{Appendix A}

The NEMO model is freely available under the CeCILL public licence. After registering at the NEMO website (http://www.nemo-ocean.eu), users should follow the procedure described in the "NEMO Quick Start Guide" section to access and run the model. The physical set-up of the configurations used in the present paper can be obtained starting from the GYRE standard configuration and modifying the following parameters.

- CPP keys:

- GYRE:

- key_gyre key_dynspg_flt key_ldfslp key_zdftke key_iomput

- NEMO-MFS-3 and NEMO-MFS-4:

- key_myconfig key_mpp_mpi key_obc key_zdfric key_dynspg_ts key_iomput

- NEMO-MFS-1 and NEMO-MFS-2:

- key_myconfig key_mpp_mpi key_obc key_zdfric key_dynspg_flt key_iomput

Namelist values should be modified according to Ta-

ble A1.
Table A1. Namelist.

\begin{tabular}{|c|c|c|c|c|c|}
\hline & GYRE & MFS-1 & MFS-2 & MFS-3 & MFS-4 \\
\hline $\ln \_z c o$ & True & \multicolumn{4}{|c|}{ false } \\
\hline ln_zps & False & \multicolumn{4}{|c|}{ true } \\
\hline ln_ana & True & \multicolumn{4}{|c|}{ false } \\
\hline ln_blk_mfs & False & \multicolumn{4}{|c|}{ true } \\
\hline ln_rnf & False & \multicolumn{4}{|c|}{ true } \\
\hline ln_bfrimp & True & \multicolumn{4}{|c|}{ false } \\
\hline nn_eos & 2 & \multicolumn{4}{|c|}{0} \\
\hline ln_traadv_tvd & True & \multicolumn{4}{|c|}{ false } \\
\hline ln_traadv_muscl & False & \multicolumn{4}{|c|}{ true } \\
\hline ln_traldf_lap & True & \multicolumn{4}{|c|}{ false } \\
\hline ln_traldf_bilap & False & \multicolumn{4}{|c|}{ true } \\
\hline ln_traldf_hor & False & \multicolumn{4}{|c|}{ true } \\
\hline ln_traldf_iso & True & \multicolumn{4}{|c|}{ false } \\
\hline ln_hpg_zco & True & \multicolumn{4}{|c|}{ false } \\
\hline ln_hpg_zps & False & \multicolumn{4}{|c|}{ true } \\
\hline ln_dynldf_lap & True & \multicolumn{4}{|c|}{ false } \\
\hline ln_dynldf_bilap & False & \multicolumn{4}{|c|}{ true } \\
\hline rn_ahm_0_blp & 0 & \multicolumn{4}{|c|}{$-5 . \mathrm{e} 9$} \\
\hline rn_aht_0 & 1000 & \multicolumn{4}{|c|}{$-3 . e 9$} \\
\hline ln_apr_dyn & False & false & false & true & true \\
\hline
\end{tabular}


Acknowledgements. This work was supported by the European Commission MyOcean 2 Project (FP7-SPACE-2011-1-Prototype Operational Continuity for the GMES Ocean Monitoring and Forecasting Service, GA 283367) and by the Italian Project RITMARE, la RIcerca iTaliana per il MARE (MIUR-Progetto Bandiera 2012-2016).

Edited by: A. Yool

\section{References}

Candela, J. and Lozano C. J.: Barotropic response of the western Mediterranean to observed atmospheric pressure forcing, in: Seasonal and Interannual Variability of the Western Mediterranean Sea, Coastal Estuarine Stud., vol. 46, edited by: La Viollette, P. E., 325-359, AGU, Washington, D. C., doi:10.1029/CE046p0325, 1994.

Cerovecki, I., Orlić, M., and Hendershott, M. C.: Aadriatic seiche decay and energy loss to the Mediterranean, Deep-sea research. Part 1. Oceanographic research papers, 44, 2007-2029, 1997.

Crépon, M.: Influence de la pression atmosphérique sur le niveau moyen de la Méditerranée Occidentale et sur le flux à travers le détroit de Gibraltar, Cah. Océanogr., 17, 15-32, 1965.

Demirov, E. and Pinardi, N.: The simulation of the Mediterranean Sea circulation from 1979 to 1993 , Part I: The interannual variability, J. Mar. Syst., 33-34, 23-50, 2002.

Drévillon, M., Bourdallé-Badie, R., Derval, C., Drillet, Y., Lellouche, J. M., Rémy, E., Tranchant, B., Benkiran, M., Greiner,E., Guinehut, S., Verbrugge, N., Garric, G., Testut, C. E., Laborie, M., Nouel, L., Bahurel, P., Bricaud, C., Crosnier, L.,Dombrosky, E., Durand, E., Ferry, N., Hernandez, F., Le Galloudec, O., Messal, F., and Parent, L.: The GODAE/Mercator-Ocean global ocean forecasting system: results, applications and prospects, J. Operational Oceanogr., 1, 51-57, 2008.

Dukowiz, J. K., Smith, R. D., and Malone, R. C.: A reformulation and implementation of the Bryan-Cox0Semtner ocean model on the connection machine, J. Atmos. Ocean Technol., 10, 195-208, 1993.

Estubier, A. and Levy, M.: Quel schema numerique pour le transport d'organismes biologiques par la circulation oceanique, Note Techniques du Pole de modelisation, Institut Pierre-Simon Laplace, 81 pp., 2000.

Fekete, B. M., Vorosmarty, C. J., and Grabs, W.: Global, composite runoff fields based on observed river discharge and simulated water balances, Tech. Rep. 22, Global Runoff Data 25 Cent., Koblenz, Germany, 1999.

Flather, R. A.: A tidal model of the northwest European continental shelf, Memories de la Societe Royale des Sciences de Liege, 6, 141-164, 1976.

Garrett, C. J. R.: Variable sea level and strait flows in the Mediterranean: A theoretical study of the response to meteorological forcing, Oceanol. Acta, 6, 79-87, 1983.

Garrett, C. J. R. and Majaess, F.: Nonisostatic response of sea level to atmospheric pressure in the Eastern Mediterranean, J. Phys. Oceanogr., 14, 656-665, 1984.

Godin, G. and Trotti, L.: Trieste-water levels 1952-1971: A study of the tide, mean level and 20 seiche activity, Environment Canado, Fisheries and Marina Services, Miscellaneous Special Publica- tion, Dept. of the Environment, Fisheries and Marine Service in Ottawa, 28, 1975.

Gomis, D., Tsimplis, M. N., Martín-Míguez, B., Ratsimandresy, A. W., García-Lafuente, J., and Josey, S. A.: Mediterranean Sea level and barotropic flow through the Strait of Gibraltar for the period 1958-2001 and reconstructed since 1659, J. Geophys. Res., 111, C11005, doi:10.1029/2005JC003186, 2006.

Gomis, D., Ruiz, S., Sotillo, M. G., Álvarez-Fanjul, E., Terradas, J.: Low frequency Mediterranean sea level variability: The contribution of atmospheric pressure and wind, Global Planet Change, 63, 215-229, 2008.

Griffies, S. M.: Fundamentals of ocean climate models, Princeton University Press, 434 pp., 2004.

Jackett, D. R. and McDougall, T. J.: Minimal Adjustment of Hydrostatic Profiles to Achieve Static Stability, J. Atmos. Ocean. Technol., 12, 381-389, 1995.

Kasumović, M.: On the influence of air pressure and wind on the Adriatic Sea level fluctuations, Hidrografski godišnjak, 1956/57, 107-121, 1958 (in Croatian).

Kourafalou, V. H. and Barbopoulos, K.: High resolution simulations on the North Aegean Sea seasonal circulation, Ann. Geophys., 21, 251-265, doi:10.5194/angeo-21-251-2003, 2003.

Lacombe, H.: Contribution à l'étude du détroit de Gibraltar, étu de dynamique, Cah. Océanogr., 12, 73-107, 1961.

Lafuente J. G., Delgado, J., Vargas, J. M., Sarhan, T., Vargas, M., and Plaza, F.: Low frequency variability of the exchanged flows through the Strait of Gibraltar during CANIGO, Deep Sea Res., 49, 4051-4067, 2002.

Lascaratos, A. and Gačić, M.: Low-Frequency Sea Level Variability in the Northeastern Mediterranean., J. Phys. Oceanogr., 20, 522533, 1990.

Leder, N. and Orlić, M.: Fundamental Adriatic seiche recorded by current meters, Ann. Geophys., 22, 1449-1464, doi:10.5194/angeo-22-1449-2004, 2004.

Le Traon, P. Y. and Gauzelin, P.: Response of the Mediterranean mean sea level to atmospheric pressure forcing, J. Geophys. Res., 102, 973-984, 1997.

Madec, G.: NEMO ocean engine, Note du Pole de modelisation, Institut Pierre-Simon Laplace (IPSL), France, No 27 ISSN No1288-1619, 2008.

Marchesiello, P., McWilliams, J. C., Shchepetkin, A.: Open boundary conditions for long term integration of regional oceanic models, Ocean Model., 3, 1-20, 2001.

Marcos, M. and Tsimplis, M. N.: Variations of the seasonal sea level cycle in southern Europe, J. Geophys. Res., 112, C12011, doi:10.1029/2006JC004049, 2007.

Mellor, G. L. and Ezer, T.: Sea level variations induced by heating and cooling: An evaluation of the boussinesq approximation in ocean models, J. Geophys. Res.-Oceans, 100, 20565-20577, doi:10.1029/95JC02442, 1995.

Molcard, A., Pinardi, N., Iskandarami, M., and Haidvogel, D. B.: Wind driven general circulation of the Mediterranean Sea simulated with a Spectral Element Ocean Model, Dynam. Atmos. Oceans, 17, 687-700, 2002.

Mosetti, F.: Considerazioni sulle cause dell'acqua alta a Venezia, Boll. Geofis. Teor. Appl., 13, 169-184, 1971.

Oddo, P. and Pinardi, N.: Lateral open boundary conditions for nested limited area models: A scale selective approach, Ocean Model., 20, 134-156, 2008. 
Oddo, P., Adani, M., Pinardi, N., Fratianni, C., Tonani, M., and Pettenuzzo, D.: A nested Atlantic-Mediterranean Sea general circulation model for operational forecasting, Ocean Sci., 5, 461-473, doi:10.5194/os-5-461-2009, 2009.

Orlić, M.: On frictionless influence of planetary atmospheric waves on the Adriatic sea level, J. Phys. Oceanogr., 13, 1301-1306, 1983.

Palumbo, A. and Manzzarella, A.: Mean sea level variations and their practical applications, J. Geophys. Res., 87, 4249-4256, 1982.

Papa, L.: A statistical investigation of low-frequency sea level variation at Genoa, Istituto Idrografico della Marina, Universita' degli strudi di Genova, F.C., 1987, Grog 6, 13 pp., 1978.

Pasaric, M., Pasaric, Z., and Orlic, M.: Response of the Adriatic sea level to the air pressure and wind forcing at low frequencies (0.01-0.1 cpd), J. Geophys. Res., 105, 11423-11439, 2000.

Pascual, A., Marcos, M., and Gomis, D.: Comparing the sea level response to pressure and wind forcing of two barotropic models: Validation with tide gauge and altimetry data. J. Geophys. Res., 113, C07011, doi:10.1029/2007JC004459, 2008.

Pinardi, N. and Flemming, N. C.: The Mediterranean Forecasting System Science Plan, EuroGOOS Publication no. 11, Southampton Oceanography Centre, 48 pp., ISBN 0-904175-35-9, 1998.

Pinardi, N., Rosati, A., and Pacanowski, R. C.: The sea surface pressure formulation of rigid lid models. Implications for altimetric data assimilation studies, J. Marine Syst., 6, 109-119, 1995.

Pinardi, N., Allen, I., Demirov, E., De Mey, P., Korres, G., Lascaratos, A., Le Traon, P.-Y., Maillard, C., Manzella, G., and Tziavos, C.: The Mediterranean ocean forecasting system: first phase of implementation (1998-2001), Ann. Geophys., 21, 3-20, doi:10.5194/angeo-21-3-2003, 2003.
Pinardi, N., Zavatarelli, M., Adani, M., Coppini, G., Fratianni, C., Oddo, P., Simoncelli, S., Tonani, M., Lyubartsev, V. Dobricic, S., Bonaduce, A.: Mediterranean Sea Largescale low-frequency ocean variability and water mass formation rates from 1987 to 2007: A retrospective analysis, doi:10.1016/j.pocean.2013.11.003, 2013.

Pinardi, N., Bonaduce, A., Navarra, A., Dobricic, S., and Oddo, P.: The mean sea level equation and its application to the Mediterranean sea, J. Climate, 27, 442-447, doi:10.1175/JCLI-D-13$00139.1,2014$.

Ponte, R. M.: Variability in a homogeneous global ocean forced by barometric pressure, Dyn. Atmos. Oceans, 18, 209-234, 1993.

Raicich, F.: On fresh water balance of the Adriatic Sea, J. Marine Syst., 9, 305-319, 1996.

Raicich, F., Orlîc, M., Vilibîc, I., Malacîc, V., A case study of the Adriatic seiches (December 1997), Il Nuovo Cimento C, 22, 715-726, 1999.

Roullet, G. and Madec, G.: salt conservation, free surface, and varying levels: a new formulation for ocean general circulation models, J. Geophys. Res., 105, 23927-23942, 2000.

UNEP: Implications of Climate Change for the Albanian Coast, Mediterranean Action Plan, MAP Technical Reports Series No. 98., 1996.

Van Leer, B.: Towards the Ultimate Conservative Difference Scheme, V. A Second Order Sequel to Godunov's Method, J. Comp. Phys., 32, 101-136, 1979.

Wakelin, S. L. and Proctor, R.: The impact of meteorology on modelling storm surges in the Adriatic Sea, Global Planet. Change, 34, 97-119, 2002.

Wunsch, C.: Bermuda sea level in relation to tides, weather, and baroclinic fluctuations, Rev. Geophys. Space Ge., 10, 1-49, doi:10.1029/RG010i001p00001, 1972. 